\title{
PROGRESIÓN DEL GLAUCOMA Y DE LA CATARATA. UNA ECUACIÓN Y DOS INCÓGNITAS
}

\section{GLAUCOMA AND CATARACT PROGRESSION. ONE EQUATION CONTAINING TWO VARIABLES}

\author{
GONZÁLEZ DE LA ROSA M ${ }^{1}$
}

Glaucoma y cataratas son enfermedades poco consideradas, que se empeñan en coincidir en la misma franja de edades. Esa época de la vida tiene el mal gusto de acumular los problemas.

Nuestro presidente, y mi maestro, el profesor Murube, habla de la herida del soldado, como un proceso frecuentemente banal, gracias a la fortaleza del organismo sobre el que asienta. A medida que la edad avanza, las defensas ceden y los problemas se acumulan, entre ellos el glaucoma y las cataratas.

El glaucoma crónico de ángulo abierto es una enfermedad de nombre francamente desagradable y evolución irreversible. Por el momento nos conformamos con intentar frenarlo, y en algunos casos detenerlo, intentando acomodar su pendiente evolutiva a las perspectivas de vida del paciente. Nuestra misión es mantener la vigilancia para preservar una visión útil durante el resto de la vida. Parece una visión muy negra de nuestro trabajo, pero no puede ser más realista.

Sabemos que la catarata es un proceso reversible en la mayor parte de los casos, pero la coincidencia de ambas enfermedades viene frecuentemente a complicar nuestra valoración de la estabilidad del paciente glaucomatoso. Aparentemente, los procedimientos de medida de la progresión de los defectos del campo visual en el glaucoma se dejarían influir fácilmente por esta coincidencia. Los análisis de tendencia miden por procedimientos matemáticos (generalmente regresión lineal), la pérdida de sensibilidad retiniana a lo largo del tiempo (1). Pero esta pérdida podría proceder de ambos orígenes, de manera que resultaría aparentemente imposible en la práctica distinguir su contribución relativa.
Por esta razón muchos autores han preferido vigilar la aparición de sucesos característicos del glaucoma, con independencia de la evolución global de la sensibilidad retiniana. De esta manera nació lo que se conoce como «análisis de eventos».

Los defensores de uno y otro procedimiento se han fustigado duramente durante años. El grupo del Institute of Ophthalmology del University College de Londres, que ha desarrollado un programa de nombre «Progressor» basado en análisis de regresión, ha afirmado ser capaz de detectar evolución bastante antes que el programa de eventos del grupo sueco (2). Este último ha contra-atacado con sorna, afirmando que el programa inglés es un excelente procedimiento para detectar cataratas y que su alta sensibilidad debe ser la consecuencia de una baja especificidad (3).

Como en tantas cuestiones la verdad no está totalmente de parte de ninguno de ellos, aunque mis simpatías se inclinaron desde un principio por los ingleses. El análisis de eventos sería un excelente procedimiento, si los defectos del campo visual fuesen estables y esencialmente focales, pero realmente son tremendamente fluctuantes, de tal manera que dos o tres campos visuales basales suelen ser totalmente insuficientes para interpretar cambios sutiles en el futuro del paciente. La focalidad, por su parte, resulta evidente en el glaucoma avanzado, pero no tanto en el incipiente, lo que ha dado lugar a interpretar que el defecto perimétrico es tardío.

El grupo inglés ha tratado con éxito de corregir esta inestabilidad recurriendo a filtros matemáticos, que mejoran la interpretación de los defectos perimétricos locales, pero no modifican la tendencia general a la pérdida de sensibilidad a lo largo del

\footnotetext{
1 Doctor en Medicina. Santa Cruz de Tenerife. España. E-mail: mgdelarosa@jet.es
} 
tiempo. El defecto medio crecería, por lo tanto, de forma indistinguible para la catarata y el glaucoma.

Recientemente uno de nuestros colaboradores, el Dr. Díaz Alemán ha analizado varios de estos programas en Aberdeen bajo la dirección de nuestro colega al Dr. Azuara-Blanco. De este estudio parece concluirse que la experiencia de los expertos suele ser más coincidente y sensible a la hora de interpretar progresión que los programas de análisis de eventos, mientras que los programas de análisis de regresión suelen ser más generosos que los expertos a la hora de interpretar progresión.

¿Es esta generosidad el resultado de su mayor sensibilidad, o por el contrario la consecuencia de confundir progresión de la catarata y progresión del glaucoma?

En otro trabajo reciente se ha observado que el cambio en el defecto medio, después de la operación de cataratas es insignificante (4). En consecuencia cabe deducir que los casos de progresión difusa que detectan los programas de análisis de regresión en sujetos glaucomatosos, y que suelen indicar pérdidas superiores a la indicada, no corresponden, en su mayor parte, a cataratas.

Nosotros hemos desarrollado un programa de análisis de tendencias con capacidad para informar el carácter difuso o focal de la progresión (5). Hemos observado que los expertos detectan esencialmente defectos focales, pero tanto los expertos como los programas de análisis de eventos no consideran a los defectos difusos como progresión.

Hace años que venimos defendiendo la varianza de pérdida (PSD en el perímetro Humphrey) como método de diagnóstico precoz, previo al defecto focal. Nuevas investigaciones, como el OHTS nos van dando la razón. De la misma manera no son los defectos focales los mejores índicadores para detectar progresión precoz. Antes de la aparición de «eventos» o de progresiones focales evidentes, el glaucoma se manifiesta como una pérdida difusa, ciertamente no siempre fácil de diferenciar de la evolución de una catarata. Solamente en glaucomas relativamente avanzados el carácter focal de la progresión resulta evidente, y de aquí surge la idea bastante generalizada de la incapacidad de la perimetría para el diagnóstico precoz de progresión.

Sin embargo, en un estudio preliminar de progresión realizado en la Universidad Complutense sobre más de 1.000 ojos glaucomatosos, en el que los profesores García Sánchez y García Feijoó me han permitido colaborar, se ha observado que más del $90 \%$ de los sujetos con reducción significativa de sensibilidad, pierden más de $0,5 \mathrm{~dB}$ al año. Por lo tanto la magnitud de la pérdida supera a lo que sería esperable por cataratas, pese a que no se observe una focalidad evidente.

La conclusión lógica es que si vigilamos el estado del cristalino, la pérdida de sensibilidad nos informará precozmente de la progresión glaucomatosa. Particularmente cuando el defecto perimétrico es escaso, la varianza relativamente elevada y el paciente no presenta una catarata densa, el deterioro perimétrico debe interpretarse como algo más que una simple sospecha de progresión glaucomatosa, aunque la focalidad de la progresión de los defectos no sea evidente.

\section{BIBLIOGRAFÍA}

1. Holmin C, Krakau CE. Regression analysis of the central field chronic glaucoma cases. A follow-up study using automatic perimetry. Arch Ophthalmol 1982; 60: 267-274.

2. Viswanathan AC, Fitzke FW, Hitchings RA. Early detection of visual field progression in glaucoma: a comparison of PROGRESSOR and STATPAC 2. Br J Ophthalmol 1997; 81: 1037-1042.

3. Heijl A, Bengtsson B, Lindgren G. Visual field progression in glaucoma. Br J Ophthalmol 1998; 82: 1097-1098.

4. Carrillo MM, Artes PH, Nicolela MT, LeBlanc RP, Chauhan BC. Effect of cataract extraction on the visual fields of patients with glaucoma. Arch Ophthalmol 2005; 123: 929-932.

5. Gonzalez de la Rosa M, Gonzalez-Hernandez M, Diaz,Aleman T. Linear regression analysis of the cumulative defect curve by sectors and other criteria of glaucomatous visual field progression. Acta Ophthalmol Scand 2006; 84: 577. 